\title{
Boosting drug Bioavailability in Men but Not Women through the Action of an Excipient ${ }^{+}$
}

\author{
Yang Mai 1,2, Diane A. I. Ashiru-Oredope ${ }^{1}$, Zhicheng Yao ${ }^{3}$, Liu Dou ${ }^{1}$, Christine M. Madla ${ }^{1}$, \\ Farhan Taherali ${ }^{1}$, Sudaxshina Murdan ${ }^{1}$ and Abdul W. Basit ${ }^{1, *}$ \\ 1 Department of Pharmaceutics, UCL School of Pharmacy, University College London, 29-39 Brunswick \\ Square, London WC1N 1AX, UK; maiy6@mail.sysu.edu.cn (Y.M.); madla.chrstn@gmail.com (D.A.I.A.-O.); \\ liu.dou.14@alumni.ucl.ac.uk (L.D.); christine.madla.16@ucl.ac.uk (C.M.M.); farhan.taherali.15@ucl.ac.uk \\ (F.T.); s.murdan@ucl.ac.uk (S.M.) \\ 2 School of Pharmaceutical Sciences (Shenzhen), Sun Yat-Sen University, Guangzhou 510275, China \\ 3 Department of General Surgery, The Third Affiliated Hospital of Sun Yat-Sen University, Guangzhou \\ 510000, China; c_madla10@yahoo.co.uk \\ * Correspondence: a.basit@ucl.ac.uk \\ + Presented at the 1st International Electronic Conference on Pharmaceutics, 1-15 December 2020; Available \\ online: https://iecp2020.sciforum.net/.
}

Published: 30 November 2020

\begin{abstract}
Active pharmaceutical ingredients are routinely formulated with a range of excipients in the manufacture of drug products. Excipients are considered to be inert components of the formulations, although recent research has contested its inactive behaviour. This study investigated the effect of the excipient polyethylene glycol 400 (PEG 400) on the oral bioavailability and intestinal permeability of cimetidine in male and female human volunteers. Aqueous solutions of cimetidine with pharmaceutically relevant concentrations of PEG 400 at $0 \% w / v$ (control), $0.3 \% w / v, 0.5 \% w / v$, $0.7 \% w / v$ and $1.0 \% w / v$ were orally administered to both sexes. Urine samples were then collected and assayed for the determination of cimetidine which reflected oral bioavailability. This human study showed that PEG 400 at $0.3 \% w / v, 0.5 \% w / v$ and $0.7 \% w / v$ concentrations significantly increased cimetidine bioavailability by $34 \%, 58 \%$ and $41 \%$ respectively, although this enhancement was only demonstrated in men and not women $(p<0.05)$. Ussing chamber transport studies with male human jejunal tissues revealed that cimetidine permeability increased by $26 \%, 48 \%$ and $29 \%$ with PEG 400 at $0.3 \% w / v, 0.5 \% w / v$ and $0.7 \% w / v$ respectively $(p<0.05)$. No such enhancement was demonstrated in female tissues $(p>0.05)$. We have shown that PEG 400 interacts with intestinal Pglycoprotein (P-gp) expression differently in males and females. The mechanistic action of PEG 400 at gut level was further investigated on human jejunal tissues following the pre-treatment of the Pgp inhibitor PSC 833 (valspodar) on the transport of cimetidine. When intestinal P-gp was inhibited, the sex- and dose-dependent modulatory effect of PEG 400 with cimetidine was completely eradicated, thus confirming that PEG 400 has a modulatory-rather than inhibitory-effect on Pgp. In sum, the widely used excipient PEG 400 is not inert at pharmaceutically relevant concentrations and its modulatory effect is demonstrated at a human clinical level. Such pharmacological effects, however, are sex- and dose-dependent via its modulation on intestinal P$\mathrm{gp}$, as evidenced by the boost in cimetidine bioavailability only in male human volunteers. As such, these findings should be carefully considered towards the co-formulation of PEG 400 with drugs that are P-gp substrates.
\end{abstract}

Keywords: gastrointestinal tract; gender response to drug therapies; sex differences in efficacy of pharmaceuticals; multidrug resistance protein 1 (MDR1); H2 receptor antagonists; oral formulations; personalized medicines 


\section{Introduction}

Peroral administration is the most convenient route of drug delivery due to its high patient compliance, flexibility in the design of dosage forms and the economical method of medicine manufacture. In order for an oral drug product to be suitably administered, the active pharmaceutical ingredient (API) must be co-formulated with a specific mixture of inactive ingredients known as excipients. The U.S. Food and Drug Administration (FDA) defines the API as a compound intended to provide the desired therapeutic effect. Excipients, however, are broadly defined as "any component of a drug product other than the API" that are benign for human consumption [1,2]. These components are not expected to have a direct pharmacological effect but to instead, alter the physical properties of an oral dosage form (such as a tablet or capsule) to facilitate drug stability, appearance or taste, for example [3].

Decades of modern pharmaceutical development have reported that excipients only contribute towards the deliberate properties of the formulation including increasing drug solubility and improve manufacturability amongst others. Despite this, a growing body of research has revealed that a number of excipients elicit biological effects which may alter treatment outcomes [2,4-8]. For example, drug alterations from modulated ATPase activity induced by excipient effects have been reported with surfactants and emulsifying polymers; Batrakova et al. demonstrated that Pluronic P85 lowered the activity of ATPase in a concentration-dependent manner and inhibited the function of intestinal efflux transporters [9,5]. In addition, polysorbates, mono- and disaccharide-based excipients have been shown to alter digoxin bioavailability via cell culture assays [10]. Other solubilising excipients such as polyethylene glycol (PEG) 2000, Cremophor RH 40, Tween 80 and Span 20 have also been studied to influence drug bioavailability in an animal model [11]. Further examples of excipient-altering effects have been discussed in the literature [6,12-15]. What is less understood, however, is the role of excipient effects in differentially modifying drug pharmacokinetics in males and females.

Indeed, the lack of equal representation of males and females in research, especially at the early drug development stage, is a matter of controversy. However, research conducted on understanding formulation performance in both males and females respectively has revealed indisputable differences [16-19]. Notably, the widely used solubilising agent polyethylene glycol 400 (PEG 400) at certain doses stimulated human intestinal motility by reducing intestinal transit time [20]. Interestingly, other excipients including D-alpha-tocopheryl-polyethylene glycol-1000 succinate (Vitamin E-TPGS) and Labrasol ${ }^{\circledR}$ did not have an effect on transit time in beagle dogs [21] nor did Vitamin E-TPGS and Capmul ${ }^{\circledR}$ in humans [22]. When co-formulated with ranitidine, the presence of PEG 400 limited the opportunity for intestinal drug absorption to occur and consequently reduced its bioavailability $[6,23,24]$. Lower doses of PEG 400 were found to have the opposite effect whereby ranitidine bioavailability increased in humans [25] and in an animal model [26,27]. Such effects, however, were dose-dependent and sex-specific, limited to males and not females.

In order to understand the potential mechanism as to why sex-related differences in drug bioavailability may occur, a number of studies have demonstrated that the intestinal efflux transporter, $\mathrm{P}$-glycoprotein (P-gp) is differentially expressed between the sexes in an animal model [28-31]. P-gp is postulated to serve as an essential protective mechanism in the intestinal luminal environment by heavily mediating oral drug absorption. In addition, P-gp has been reported as a significant contributor to sex differences in pharmacokinetic response [32]. The fact that the same drug bioavailability enhancing effect of PEG 400 was observed for ranitidine in male humans and rats in three separate studies indicate that the mechanism responsible for this sex-specific effect may common to both species. This, however, is under the assumption that PEG 400 modulates other BCS III drugs or drugs affected by membrane transporters (predominantly BCS/BDDCS II and III drugs) [33].

To identifying whether sex-specific differences in excipient-drug modulation translate from animals to humans at a physiological level, this study investigated the effects of pharmaceutically relevant concentrations of PEG 400 on cimetidine bioavailability in both healthy male and female subjects. Cimetidine was chosen as a model drug as it is a $\mathrm{H}_{2}$-antagonist primarily absorbed in the 
small intestine and is a substrate of P-gp which suggests that its bioavailability is vulnerable to factors influencing intestinal transit or absorption [34]. The influence of PEG 400 on cimetidine permeability and the quantification of P-gp expression in the healthy human intestinal tissues was also investigated via Ussing chamber studies and Western blot respectively.

\section{Materials and Methods}

\subsection{Materials}

Cimetidine, polyethylene glycol 400, glacial acetic acid and sodium acetate trihydrate were obtained from Sigma Aldrich (Dorset, UK). PSC 833 (valspodar) was provided by Aladdin (Shanghai, China). HPLC grade water and acetonitrile were purchased from Fisher Scientific (Loughborough, UK). NuPAGE LDS Sample Buffer, Tris Buffered Saline, 10X Solution, NuPAGE MOPS SDS Running Buffer (20×), NuPAGE Transfer Buffer (20×) and Super Signal West Pico Chemiluminescent Substrate were purchased from Thermo Scientific (Paisley, UK). Tween 20, Bovine Serum Albumin and Monoclonal Anti- $\beta$ actin were obtained from Sigma Aldrich (Dorset, UK). TBE Running Buffer (5×) and 10× TBE Electrophoresis Buffer were bought from Thermo Scientific (Paisley, UK). All other chemicals and kits are noted individually in the following methods.

\subsection{Human Clinical Study}

\subsubsection{Protocol}

Oral solutions consisting of $150 \mathrm{~mL}$ of water containing $150 \mathrm{mg}$ of cimetidine (GlaxoSmithKline, Harlow, UK) was co-formulated with PEG 400 one of the following quantities; $0 \%$ (control), $0.3 \%$, $0.5 \%, 0.7 \%$ and $1 \% w / v$ (corresponding to $0 \mathrm{~g}, 0.5 \mathrm{~g}, 0.75 \mathrm{~g}, 1.0 \mathrm{~g}$ and $1.5 \mathrm{~g}$ ) and prepared under GMP conditions. A washout period of one week was given in between dosing. Twelve healthy volunteers ( 6 males and 6 females) with the following parameters were included; Age: males (24-40 years; median 26 years), females (23-27 years; median 24 years); Weight: males (55-90 kg; median $62 \mathrm{~kg}$ ), females (50-76 kg; median $60 \mathrm{~kg}$ ); and Height: males (1.66-1.84 m; median $1.73 \mathrm{~m}$ ), females 1.58-1.70 $\mathrm{m}$; median $1.69 \mathrm{~m}$ ). All human subjects participated in a random six-way cross over study after giving informed written consent. All subjects were within the age criteria of 20-60 years old, non-smokers, and declared themselves healthy with no history of GI disease. The experimental protocol was approved by The Joint University College London/University College London Hospital (UCL/UCLH) Committees on the Ethics of Human Research in the United Kingdom. The study was conducted in accordance with the Helsinki guidelines for ethics in research (1965) and its subsequent revisions up to the revision of Edinburgh 2000.

The volunteers reported to the study centre after an overnight fast and each received, on six separate occasions, $150 \mathrm{~mL}$ of a cimetidine solution containing the required dose of PEG 400 . A standardised lunch consisting of a two-piece cheese or egg sandwich, a $32.5 \mathrm{~g}$ packet of crisps and a $250 \mathrm{~mL}$ juice drink was provided $4 \mathrm{~h}$ following oral administration. Water was available ad libitum from this point onwards.

Cumulative urine samples were collected throughout the course of each study day. This involved the collection and measurement of urine output over the following time periods: $0 \mathrm{~h}$ (predose), 0-2 h, 2-4 h, 4-6 h, 6-12 h and 12-24 h. For each time point, a $20 \mathrm{~mL}$ aliquot was retained and stored at $-20^{\circ} \mathrm{C}$.

Cumulative urinary excretion can serve as a surrogate to determine oral bioavailability as per the Code of Federal Regulations [35]. The guideline states that in an in vivo drug bioavailability study, the drug elimination period should be at least three times the half-life of the active drug ingredient measured in the blood or urine or at least three times the half-life of the acute pharmacological effect. As the half-life of cimetidine is approximately $2 \mathrm{~h} \mathrm{[36],} \mathrm{the} \mathrm{collection} \mathrm{of} \mathrm{urine}$ within time periods in $24 \mathrm{~h}$ for analysis of unchanged cimetidine excreted can infer for oral bioavailability. 


\subsubsection{Urine Samples Analytics}

Urine samples were assayed for the amount of unchanged cimetidine. Frozen aliquots were thawed at room temperature and $0.65 \mathrm{~mL}$ of each sample was added to $0.65 \mathrm{~mL}$ of a mixture of 20:80 acetonitrile:water in duplicate. After thorough vortex-mixing, a $10 \mu \mathrm{L}$ aliquot of each solution collected at the aforementioned time points was injected into a Luna SCX (Phenomenex, Macclesfield, UK) HPLC column using a validated HPLC-UV method [37]. The mobile phase was 20:80 acetonitrile: $0.1 \mathrm{M}$ sodium acetate with a flow rate of $2 \mathrm{~mL} / \mathrm{min}$. Calibration standards were prepared with blank human urine spiked with drug and diluted by 50\% with 20:80 acetonitrile:water.

\subsection{The Effect of PEG 400 on Intestinal Absorption}

\subsubsection{Human Jejunal Collection and Participant Information}

A total of 12 Chinese patients ( 6 males and 6 females) diagnosed with pancreatic cancer at the Third Affiliated Hospital of Sun Yat-sen University in Guangzhou, China between July 2019 and March 2020 were enrolled in the study and signed informed consent for jejunal tissue collection. All collected tissues were macroscopically healthy. The experimental protocol (number [2016]2-16) was approved by The Research Ethics Committee of the Third Affiliated Hospital of Sun Yat-sen University. The clinical characteristics of each patient including age, sex, preoperative tumour size, tumour number and the familial history of cancer were recorded (Table 1).

Table 1. Patient information who donated jejunal tissues for permeability studies.

\begin{tabular}{ccc}
\hline Sample Information & Males & Females \\
\hline Sample region & Jejunum & Jejunum \\
Number of samples & 9 & 9 \\
Sample type & healthy tissue & healthy tissue \\
Age range (year) & $44-63$ & $48-65$ \\
Average age (year) & 54 & 58 \\
Weight range (kg) & $64-79$ & $49-65$ \\
Average weight $\mathbf{( k g )}$ & 72 & 57 \\
\hline
\end{tabular}

\subsubsection{Jejunal Tissue Preparation}

The tissues were prepared for the permeability study on the day of collection. Each segment was washed with cold Krebs-Bicarbonate Ringer's (KBR) solution and put into beakers with KBR solution on ice. This consisted of $10 \mathrm{mM}$ D-glucose, $1.2 \mathrm{mM}$ calcium chloride $\left(\mathrm{CaCl}_{2}\right), 1.2 \mathrm{mM}$ magnesium chloride $\left(\mathrm{MgCl}_{2}\right), 115 \mathrm{mM}$ sodium chloride $(\mathrm{NaCl}), 25 \mathrm{mM}$ sodium bicarbonate $\left(\mathrm{NaHCO}_{3}\right), 0.4 \mathrm{mM}$ monopotassium phosphate $\left(\mathrm{KH}_{2} \mathrm{PO}_{4}\right), 2.4 \mathrm{mM}$ dipotassium phosphate $\left(\mathrm{K}_{2} \mathrm{HPO}_{4}\right)$ with the $\mathrm{pH}$ of the solution adjusted to 7.4 with sodium hydroxide $(\mathrm{NaOH})$ or hydrochloric acid $(\mathrm{HCl})$. The tissues were then cut into 6 sections (of at least $50 \mathrm{~mm}^{2}$ in size) and placed on an ice-cold glass plate. The serosal layer was gently removed with a scalpel to expose the mucosa-side.

\subsubsection{Ussing Chamber Set-Up}

Following its preparation, the mucosal tissues were mounted as flat sheets on a $0.29 \mathrm{~cm}^{2}$ segment holder with needles for stabilisation and placed in a vertical UC-6M Ussing Chamber (Kingtech, Beijing, China). $5 \mathrm{~mL} \mathrm{KBR}$ solution was added to each compartment of the Ussing Chamber and the solutions were supplied with an $\mathrm{O}_{2} / \mathrm{CO}_{2}$ gas mixture $(95 \% / 5 \%)$. The chambers were tightly screwed and the entire assembly was controlled at $37^{\circ} \mathrm{C}$.

To evaluate tissue integrity during experiments, tissue transepithelial electrical resistance (TEER) was measured using a VCC MC6 MultiChannel Voltage-Current Clamp (Physiologic Instruments, San Diego, CA, USA) coupled with the Ussing chamber system. Any jejunal tissue that showed a TEER value lower than $40 \Omega \cdot \mathrm{cm}^{2}$ at the beginning of the experiment was regarded as poorly viable and excluded from the study. Whenever TEER values decreased by more than $15 \%$ from the 
original value (measured at the end of a 30 min equilibration period), the tissue was considered not to be viable and also eliminated from the investigation.

\subsubsection{Transport Study}

After the equilibrium period, the experiment was initiated by replacing the blank KBR solution in the donor compartment with pre-warmed $5 \mathrm{mg} / \mathrm{mL}$ cimetidine solution with and without PEG 400 at $0.3 \% w / v, 0.5 \% w / v, 0.7 \% w / v$ and $1.0 \% w / v$ concentrations. To investigate the permeability of cimetidine co-formulated with different doses of PEG 400, PSC 833, a validated P-gp inhibitor, at the dose of $10 \mu \mathrm{M}$ was placed into the donor chamber $15 \mathrm{~min}$ prior to the addition of cimetidine \pm PEG 400 solutions. $100 \mu \mathrm{L}$ of the receiver solution was taken to determine the drug concentration by HPLC every $30 \mathrm{~min}$ and replaced with an equal volume of a heated blank KBR solution. The receiver solution samples were kept at $4{ }^{\circ} \mathrm{C}$ until analysed to quantify the concentration of cimetidine by HPLC as described in Section 2.2.2.

\subsubsection{Calculation}

The apparent permeability coefficient $\left(P_{a p p}\right)$ in each experiment, in $\mathrm{cm} / \mathrm{s}$, was calculated using the following equation:

$$
P_{a p p}=\frac{Q}{C \times A \times t}
$$

where; $Q(\mu \mathrm{mol})$ is the total amount of drug that permeated to the receiver compartment throughout the incubation time; $C(\mu \mathrm{mol} / \mathrm{mL})$ is the initial drug concentration in the donor side; $A\left(\mathrm{~cm}^{2}\right)$ is the diffusion area of the Ussing Chamber and; $t$ (s) is the duration of experiment.

\subsection{Human Intestinal Efflux Transporter Expression}

\subsubsection{Measurement of Protein Levels by Western Blotting}

The human mucosal tissues of each jejunal intestinal segment (200 mg respectively) from male and female volunteers were cut into small pieces and homogenised in $10 \mathrm{~mL}$ lysis buffer at 10,00 rpm for $20 \mathrm{~s}$ on ice with a T18 digital ULTRA-TURRAX ${ }^{\circledR}$ (IKA, Wilmington, NC, USA). The tissue homogenates were incubated at $4{ }^{\circ} \mathrm{C}$ for $2 \mathrm{~h}$ and centrifuged at $10,000 \mathrm{rpm}$ for $10 \mathrm{~min}$. The total tissue protein was collected in the supernatants and its concentration was subsequently determined with the Pierce ${ }^{\mathrm{TM}}$ BCA Assay Protein kit (ThermoFisher, Loughborough, UK) according to the manufacturer's instructions.

To measure the targeted protein level, samples containing $25 \mu \mathrm{g}$ total protein were suspended in lithium dodecyl sulfate (LDS) sample loading buffer (Invitrogen, Carlsbad, CA, USA) and denatured for $10 \mathrm{~min}$ at $70{ }^{\circ} \mathrm{C}$. As a molecular weight marker, $5 \mu \mathrm{L}$ of Sharp Pre-Stained protein standard (Invitrogen) was loaded in the first well of each gel. Proteins loaded in each well were separated by electrophoresis in a NuPAGE ${ }^{\mathrm{TM}}$ Novex $^{\mathrm{TM}} 4-12 \%$ Bis-Tris gel (Invitrogen, Loughborough, UK) and transferred to a nitrocellulose membrane with XCell SureLock ${ }^{\mathrm{TM}}$ Mini-Cell Electrophoresis System (Invitrogen, Loughborough, UK) according to the manufacturer's instructions. Nitrocellulose membranes were blocked with $3 \%$ bovine serum albumin (BSA) in $0.1 \%$ Tween 20 tris-buffered saline (TBS-T) and incubated for $1 \mathrm{~h}$ at room temperature $\left(20{ }^{\circ} \mathrm{C}\right)$. For the detection of targeted P-gp protein (human monoclonal anti-P-gp; C-494 3:200, Enzo Life Science, Exeter, UK) and reference protein (anti- $\beta$ actin human monoclonal antibody; 1:2000, ThermoFisher, Loughborough, UK), gel protein blots were incubated for $1 \mathrm{~h}$ at room temperature with the respective primary antibodies diluted in 3\% BSA in TBS-T. Bound antibodies were detected with affinitypurified rabbit anti-human immunoglobulin (IgG) coupled to the secondary antibody, horseradish peroxidase (Sigma Aldrich, Dorset, UK), diluted 1:5000 in 3\% BSA in TBS-T. After $1 \mathrm{~h}$ incubation with the secondary antibody conjugated with horseradish peroxidase, protein bands were visualised by chemiluminescence detection with Pierce ${ }^{\mathrm{TM}}$ ECL Western Blotting Substrate (ThermoFisher, Loughborough, UK) and photographed with a ChemiDoc XRS camera (Bio-Rad, Hertfordshire, UK). 
P-gp and reference protein bands were qualified using the Image Lab ${ }^{\mathrm{TM}}$ software (Bio-Rad, Hertfordshire, UK). To calculate the relative P-gp contents in the different samples, the reference protein band in each sample was set to 1 , and the intensity of the P-gp band was measured relative to it.

2.4.2. Measurement of mRNA Expression by Real-Time Reverse-Transcription Polymerase Chain Reaction

Following collection of human samples (Section 2.3.1), the tissues were kept in RNA later ${ }^{\circledR}$ Stabilization Solution (Thermofisher, Loughborough, UK). Total RNA in each intestinal sample was isolated and purified with PureLink ${ }^{\circledast}$ RNA Mini Kit (Thermofisher, Loughborough, UK) and RNA concentration was measured with Nanodrop 2000 (Thermofisher, Loughborough, UK) according to the manufacturer's instructions.

The quantification of the target RNA was then conducted as follows; 1 mg total RNA of each sample was reverse transcribed using the iScript ${ }^{\mathrm{TM}}$ cDNA Sythesis Kit (Bio-Rad, Hertfordshire, UK). To quantify the amount of P-gp relative $m d r$ mRNA, real-time PCR was performed on the 7500 Real Time PCR System (Applied Biosystems, Thermofisher, Loughborough, UK) using the method described in the study by MacLean (MacLean et al., 2008). Briefly, $50 \mu \mathrm{L}$ PCR reaction contained 25 $\mu \mathrm{L}$ of PowerUp ${ }^{\mathrm{TM}}$ SYBR Green PCR Master Mix (Thermofisher, Loughborough, UK), $500 \mathrm{nM}$ each of forward and reverse primers, and $1 \mu \mathrm{g}$ of cDNA. $\beta$-actin was used for normalisation and amplification of $1 \mu \mathrm{g}$ cDNA respectively. Real-time PCR was carried out in 96 well PCR plates (Thermofisher, Loughborough, UK). The amplification program for all genes consisted of one preincubation cycle at $95{ }^{\circ} \mathrm{C}$ with a $10 \mathrm{~min}$ hold, followed by 45 amplification cycles with denaturation at $95{ }^{\circ} \mathrm{C}$ with a $10 \mathrm{~s}$ hold, an annealing temperature of $50{ }^{\circ} \mathrm{C}$ with a $10 \mathrm{~s}$ hold, and an extension at 72 ${ }^{\circ} \mathrm{C}$ with a $10 \mathrm{~s}$ hold. Amplification was followed by a melting curve analysis which ran for one cycle with denaturation at $95^{\circ} \mathrm{C}$ with a $1 \mathrm{~s}$ hold, annealing at $65^{\circ} \mathrm{C}$ with a $15 \mathrm{~s}$ hold and melting at $95{ }^{\circ} \mathrm{C}$ with a $1 \mathrm{~s}$ hold. Distilled water was included as a negative control in each run to access specificity of primers and possible contaminants.

Primers were designed by primer-BLAST searching with publicly available sequence information of the GeneBank of the National Center for Biotechnology Information (NCBI) (Table 2) and purchased from Eurofins (Eurofins Genomics, Ebersberg, Germany). Relative expression of mRNA in different intestinal segments were calculated using 7500 software (version 2.0.6, Thermofisher, Loughborough, UK). The average of the threshold cycle $(\mathrm{Ct})$ values for tested genes and the internal control ( $\beta$-actin) was taken. The differences between $\mathrm{Ct}$ values for tested genes and internal control $(\Delta \mathrm{Ct})$ were then calculated for all the experimental samples.

Table 2. Primers used for the analysis of efflux transporter gene expression in human intestine by real-time qPCR.

\begin{tabular}{|c|c|c|c|c|}
\hline Gene & & Primer $\left(5^{\prime}-3^{\prime}\right)$ & Amplicon (bp) & Genebank Accession \\
\hline$m d r 1$ & $\begin{array}{l}\text { Forward } \\
\text { Reverse }\end{array}$ & $\begin{array}{l}\text { GAGAGATCCTCACCAAGCGG } \\
\text { ATCATTGGCGAGCCTGGTAG }\end{array}$ & 122 & NM_00927 \\
\hline B-actin & $\begin{array}{l}\text { Forward } \\
\text { Reverse }\end{array}$ & $\begin{array}{l}\text { GGATTCCTATGTGGGCGACGA } \\
\text { GCGTACAGGGATAGCACAGC }\end{array}$ & 282 & NM_001101 \\
\hline
\end{tabular}

\subsection{Statistical Analysis}

The experiments were performed at least six times and data were expressed as mean \pm standard deviation (S.D.). The results obtained for the cumulative excretion of cimetidine in urine and the fluorescence polarisation for male and female human volunteers were subjected to one-way ANOVA. This was conducted to assess the effect of the different PEG 400 concentrations on the bioavailability of cimetidine in males and females separately. A post-hoc Tukey test with IBM SPSS Statistics 19 (SPSS Inc., Chicago, IL, USA) was then applied. A minimum $p$-value of 0.05 was used as a significance 
level for the tests. The relationship between efflux transporter protein levels and mRNA expression was investigated using Pearson product-moment correlation coefficient $(r)$.

\section{Results}

The bioavailability of cimetidine in human subjects indicated by the cumulative amounts of unchanged cimetidine excreted in urine over $24 \mathrm{~h}$ is shown in Table 3. In the absence of PEG 400 (control groups), the total mean amount of cimetidine that was excreted in urine was similar in both males and females at $48 \%$ and $47 \%(w / w)$ of the administered dose respectively.

The dose-dependent influence of PEG 400 on cimetidine excretion in urine in humans is shown in Figure 1. The percentage of variation of the cumulative unchanged urinary excretion of cimetidine is calculated relative to the control (0 $\mathrm{g}$ PEG 400). A bell-shaped curve was garnered from the coformulation of $0.3 \% w / v, 0.5 \% w / v, 0.7 \% w / v$ and $1.0 \% w / v$ PEG 400 on the unchanged excreted amount of cimetidine. Such an effect at each concentration, however, is only demonstrated in males, but not in females. In males, unchanged excreted amount in cimetidine increased by $34 \%, 58 \%$ and $41 \%$ in the presence of $0.3 \% w / v, 0.5 \% w / v$ and $0.7 \% w / v$ PEG $400(p<0.05)$. No modulation in cimetidine urinary excretion when compared with the control was seen in females. The co-formulation of $1.0 \%$ $w / v$ PEG 400 showed no sex differences between males and females although decreased cimetidine urinary excretion comparable by $-14 \%$ and $-22 \%$ respectively $(p>0.05)(n=6)$.

Table 3. Cumulative amount of cimetidine excreted by human volunteers in $24 \mathrm{~h}$.

\begin{tabular}{|c|c|c|c|c|c|c|c|c|c|c|}
\hline \multirow{4}{*}{ Volunteer } & \multicolumn{10}{|c|}{ Cumulative Amount of Cimetidine Excreted in $24 \mathrm{~h}(\mathrm{mg})$} \\
\hline & \multicolumn{10}{|c|}{ Dose of PEG $400(\% w / v)$} \\
\hline & \multicolumn{2}{|c|}{0} & \multicolumn{2}{|c|}{0.3} & \multicolumn{2}{|c|}{0.5} & \multicolumn{2}{|c|}{0.7} & \multicolumn{2}{|c|}{1.0} \\
\hline & Males & Females & Males & Females & Males & Females & Males & Females & Males & Females \\
\hline 1 & 71 & 60 & 98 & 70 & 111 & 50 & 119 & 50 & 76 & 43 \\
\hline 2 & 61 & 67 & 124 & 89 & 142 & 74 & 80 & 95 & 54 & 90 \\
\hline 3 & 73 & 98 & 67 & 63 & 93 & 85 & 100 & 84 & 56 & 108 \\
\hline 4 & 79 & 67 & 88 & 64 & 90 & 59 & 111 & 62 & 67 & 33 \\
\hline 5 & 93 & 66 & 96 & 60 & 120 & 70 & 129 & 75 & 62 & 50 \\
\hline 6 & 57 & 64 & 88 & 39 & 108 & 55 & 75 & 56 & 54 & 19 \\
\hline Mean & 72 & 70 & 94 & 64 & 111 & 66 & 102 & 70 & 62 & 57 \\
\hline S.D. & 13 & 14 & 24 & 12 & 24 & 13 & 21 & 18 & 6 & 32 \\
\hline$\%$ difference & - & - & +29 & -9 & +53 & -7 & +41 & 0 & -15 & -19 \\
\hline
\end{tabular}

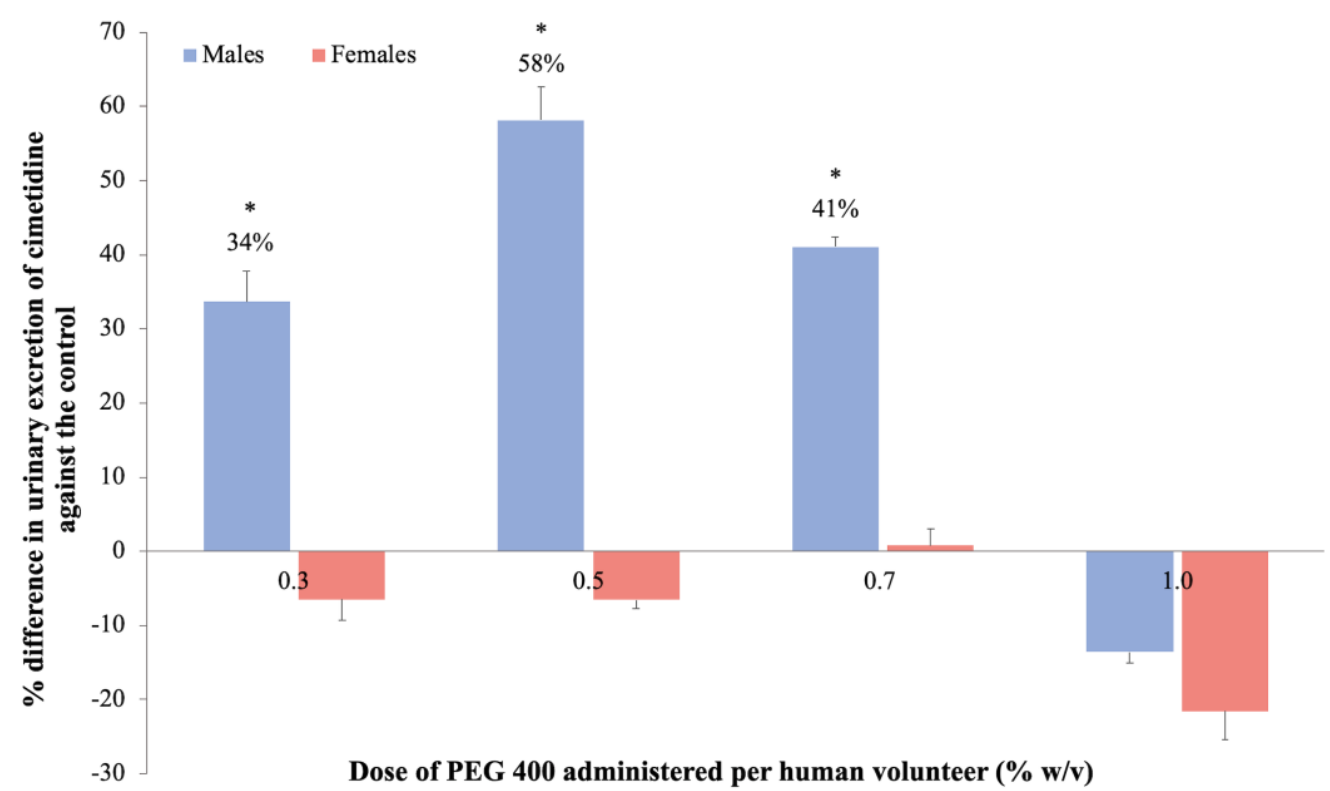

Figure 1. Percentage difference of the cumulative urinary excretion of cimetidine with different doses of PEG 400 against the control (cimetidine alone) in male and female human volunteers (mean \pm S.D., $n=6) .{ }^{*}$ Denotes statistical significance against the control $(p<0.05)$. 
The human jejunal permeability of cimetidine via Ussing chamber studies reflected in vivo drug performance. Figure 2 and Table 4 showed that $0.3 \% w / v, 0.5 \% w / v$ and $0.7 \% w / v$ PEG 400 significantly increased cimetidine permeability by $26 \%, 48 \%$ and $29 \%$ respectively when compared with the control $(0 \%$ PEG 400) $(p<0.05)$. Again, such an effect was only demonstrated in male jejunal tissues. Female jejunal tissues maintained similar permeability values of cimetidine across different PEG 400 concentrations.

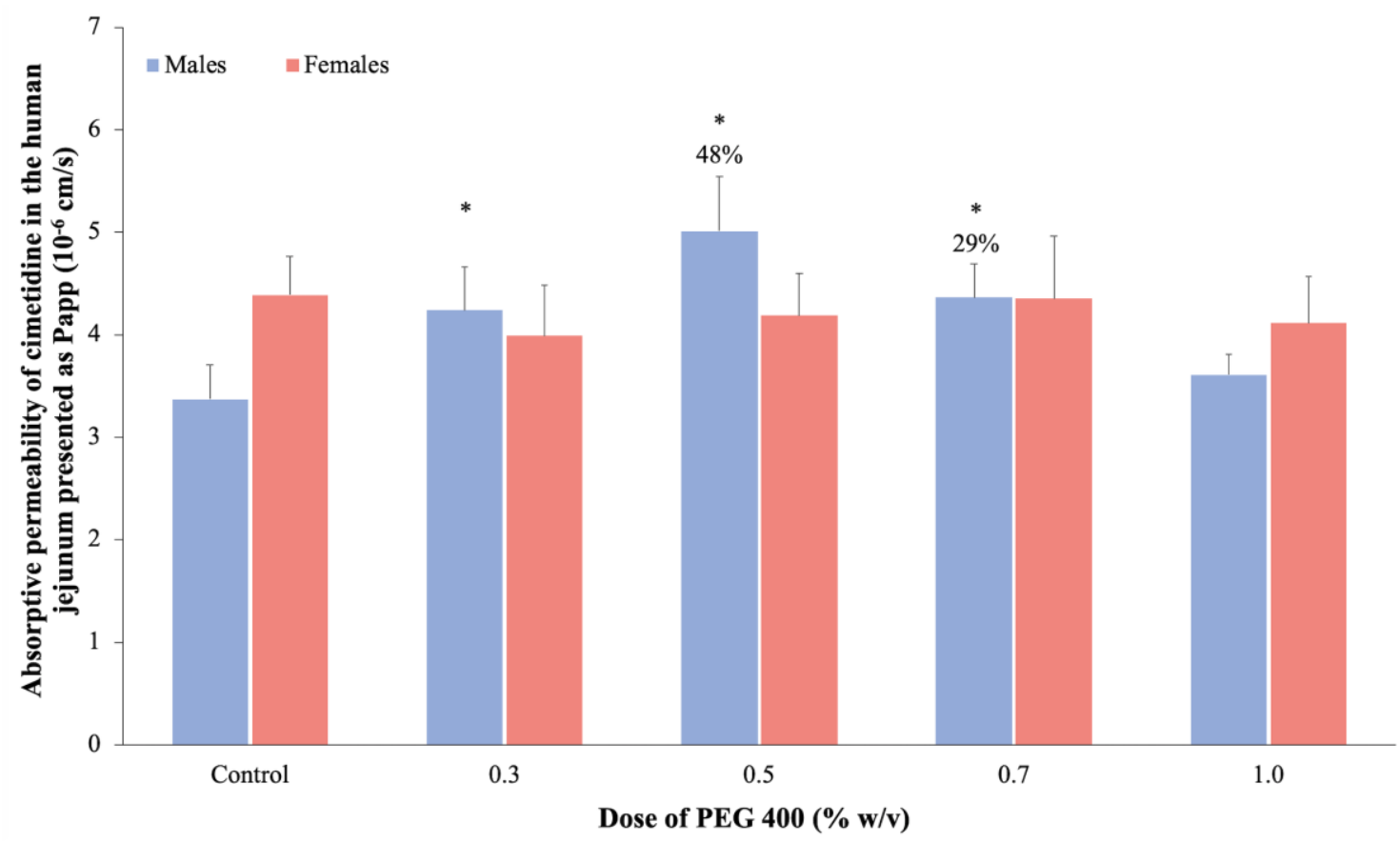

Figure 2. Permeability of cimetidine in male and female human jejunal tissues with different doses of PEG 400 against the control (cimetidine alone) (mean \pm S.D., $n=6$ ). ${ }^{*}$ Denotes statistical significance against the control $(p<0.05)$.

The effect of PEG 400 on the absorptive transport of cimetidine in the PSC 833 pre-treated human male and female jejunal tissues is shown in Figure 3 and Table 5. Pre-incubation with PSC 833 significantly increased cimetidine jejunal absorption in females by $19 \%(n=3)(p<0.05)$. This, however, was a conservative difference when compared with males. A considerable and significant increase in cimetidine absorption of $62 \%$ was demonstrated in males when compared to the transport of cimetidine alone $(p<0.05)$. The overall impact of PSC 833 is demonstrated as a net increase in cimetidine absorption (i.e., a decrease in efflux ratio), albeit human male jejunal tissues were greatly affected in comparison to females.

No sex-specific effect of different doses of PEG 400 on cimetidine transport, however, was seen following P-gp inhibition with PSC 833 (Figure 4 and Table 5). No difference was demonstrated in the permeability of cimetidine in the presence of $0.3 \% w / v, 0.5 \% w / v, 0.7 \% w / v$ and $1 \% w / v$ PEG 400 concentrations and reflected what was seen in the control ( $0 \%$ w/v PEG 400).

Table 4. The apparent permeability coefficient $\left(P_{a p p}\right)$ of cimetidine in the absence and presence of PEG 400 in the male and female jejunal segments (mean \pm S.D., $n=6$ ). ${ }^{*}$ Values are statistically different between the control (cimetidine only) and tested PEG groups at $p<0.05$.

\begin{tabular}{|c|c|c|c|c|c|}
\hline \multirow{2}{*}{$P_{a p p}\left(\times 10^{-6} \mathrm{~cm} / \mathrm{s}\right)$} & \multicolumn{5}{|c|}{ Doses of PEG $400(\% w / v)$} \\
\hline & 0 & 0.3 & 0.5 & 0.7 & 1.0 \\
\hline Males & $3.37 \pm 0.34$ & $4.24 \pm 0.42 *$ & $5.01 \pm 0.53 *$ & $4.36 \pm 0.33 *$ & $3.61 \pm 0.20$ \\
\hline Females & $4.39 \pm 0.38$ & $3.99 \pm 0.49$ & $4.19 \pm 0.42$ & $4.35 \pm 0.62$ & $4.11 \pm 0.45$ \\
\hline
\end{tabular}




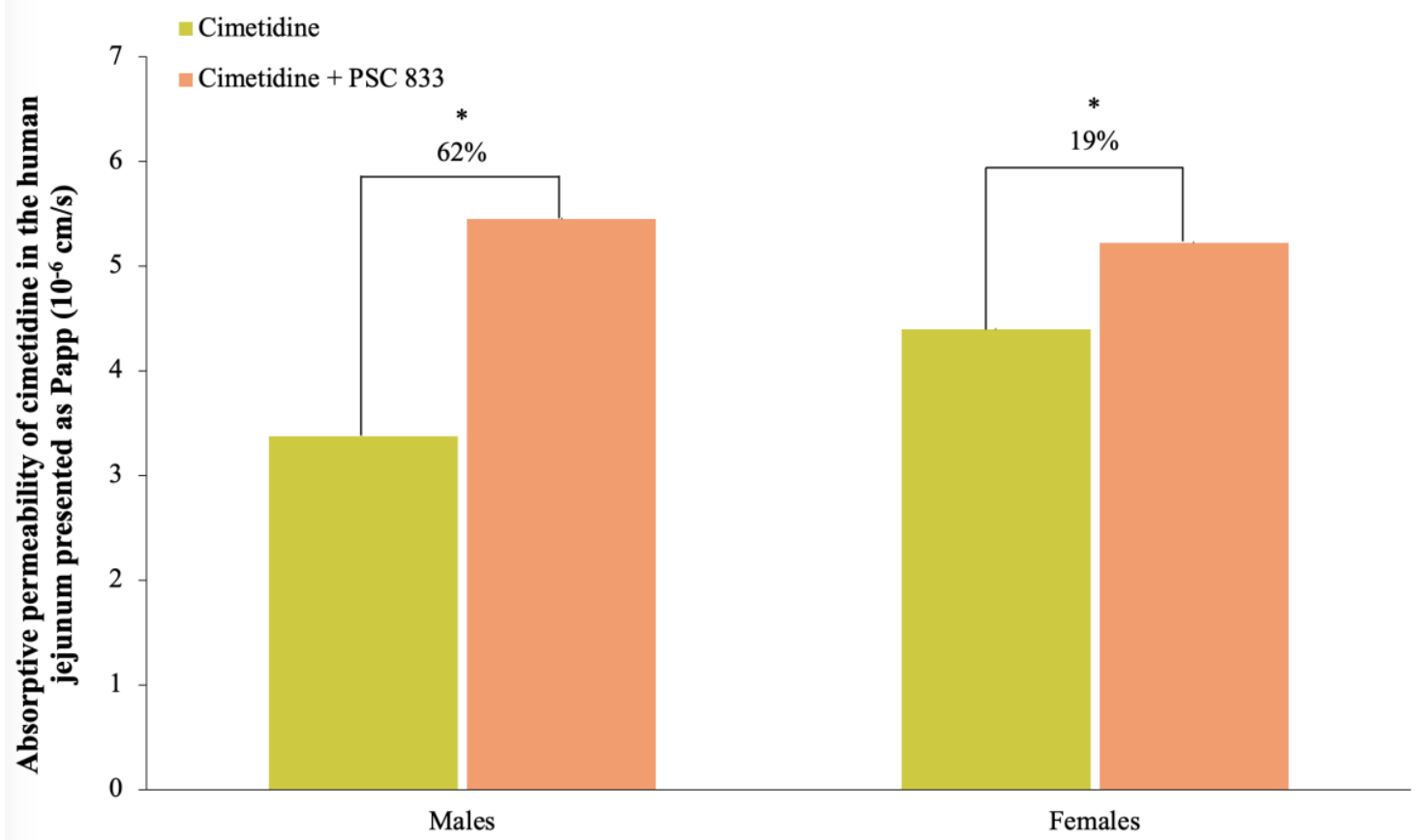

Figure 3. Permeability of cimetidine in male and female human jejunal tissues in the absence and presence of PSC 833 (mean \pm S.D., $n=6$ ). ${ }^{*}$ Denotes statistical significance against the control $(p<0.05)$.

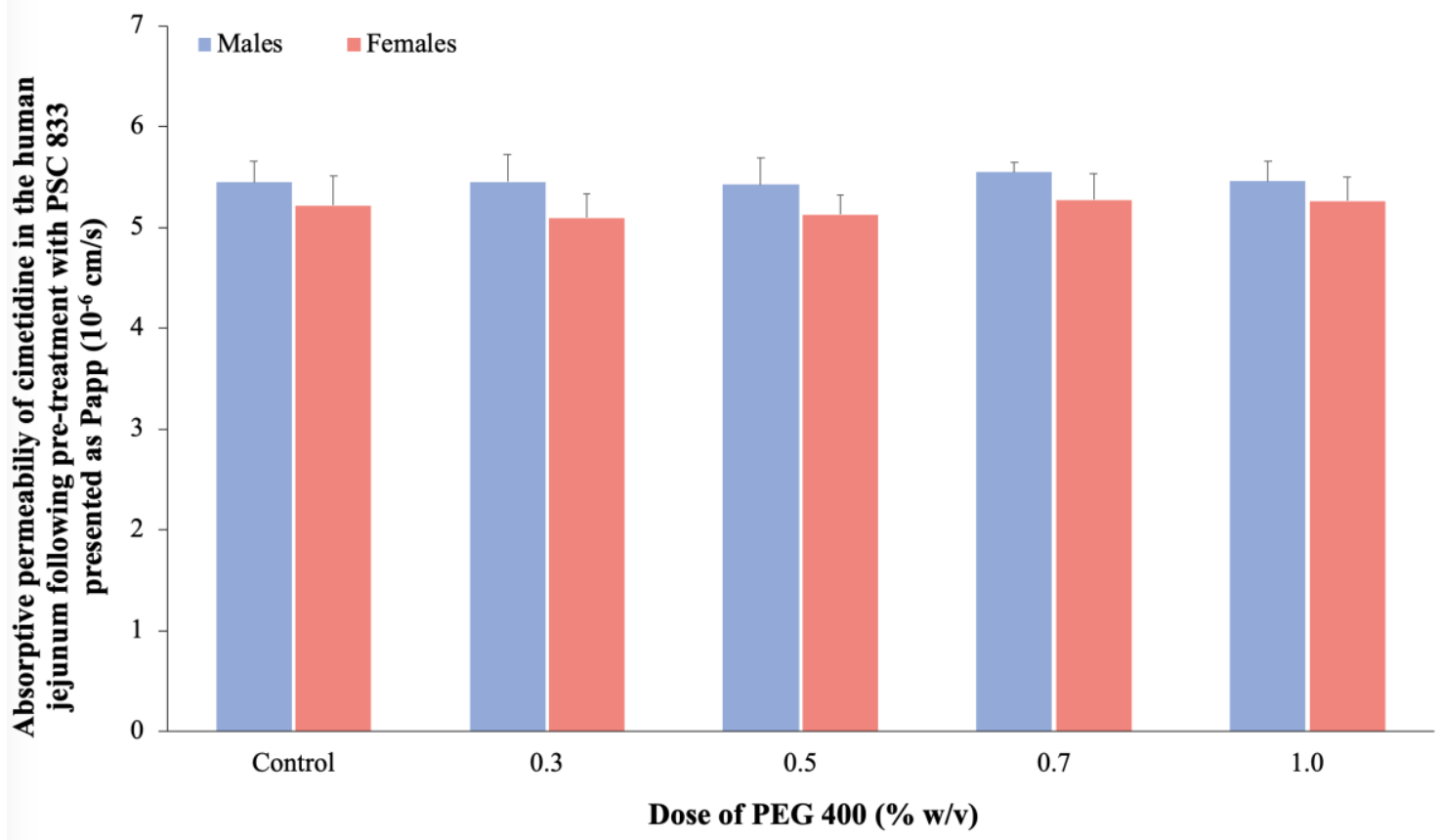

Figure 4. Permeability of cimetidine in male and female human jejunal tissues with different doses of PEG 400 following PSC 833 pre-treatment.

Table 5. The apparent permeability coefficient $\left(P_{a p p}\right)$ of cimetidine in the absence and presence of PEG 400 in the male and female jejunal segments after PSC 833 (a P-gp inhibitor) pre-treatment (mean \pm S.D., $n=3) .{ }^{*}$ Values are statistically different between the control and tested PEG groups at $p<0.05$.

\begin{tabular}{cccccc}
\hline \multirow{2}{*}{$\boldsymbol{P}_{\text {app }}\left(\times \mathbf{1 0}^{-\mathbf{6}} \mathbf{~ c m} / \mathbf{s}\right)$} & \multicolumn{5}{c}{ Doses of PEG 400 $(\mathbf{\%} \mathbf{w} / \mathbf{v})$} \\
\cline { 2 - 6 } & $\mathbf{0}$ & $\mathbf{0 . 3}$ & $\mathbf{0 . 5}$ & $\mathbf{0 . 7}$ & $\mathbf{1 . 0}$ \\
\hline Males & $5.45 \pm 0.20$ & $5.45 \pm 0.27$ & $5.42 \pm 0.27$ & $5.55 \pm 0.10$ & $5.46 \pm 0.20$ \\
Females & $5.22 \pm 0.30$ & $5.09 \pm 0.23$ & $5.13 \pm 0.20$ & $5.27 \pm 0.26$ & $5.26 \pm 0.24$ \\
\hline
\end{tabular}


In terms of P-gp and mRNA ( $m d r 1)$ abundance in the human jejunum, an obvious sex difference can be seen in Figure 5. Both P-gp and $m d r 1$ relative abundance in male tissues were significantly higher than female counterparts by $66 \%$ and $68 \%$ respectively.
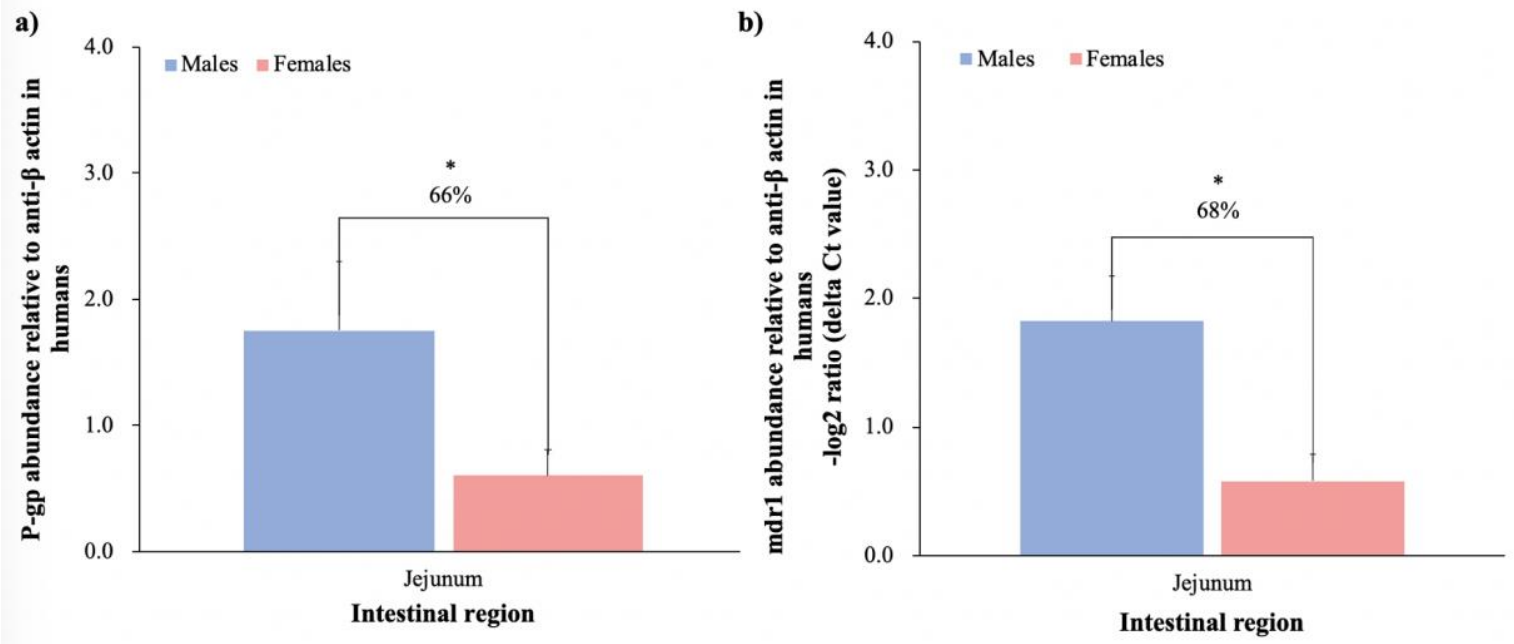

Figure 5. Relative quantification of (a) P-gp and (b) mRNA ( $m d r 1$ ) abundance in male and female human jejunal segments. The levels of protein and mRNA are normalised to $\beta$-actin (mean \pm S.D., $n=$ 6). * Denotes statistical significance between male and female groups at $p<0.05$.

\section{Discussion}

The study herein aimed to explore the effects of the pharmaceutical excipient, PEG 400, on the bioavailability of BCS III drug cimetidine in male and female subjects, and its small intestinal permeability in human tissues. As there is a good correlation between plasma and urine levels of cimetidine in humans, in this case the cumulative urinary excretion of cimetidine provides a measure of its oral bioavailability [36]. In the absence of PEG 400 (control groups), the total mean amount of cimetidine that was excreted in urine was similar in both males and females at $48 \%$ and $47 \%(w / w)$ of the administered dose respectively. These results are comparable to other in vivo studies following oral administration where the level of excreted unchanged cimetidine in the urine of healthy volunteers was $47 \%$ (male $n=10$ and female $n=2$ ) [38] and 48\% (male $n=24$ ) [39].

In terms of the impact of excipients on drug performance, previous studies have demonstrated PEG 400 at low doses can modulate the bioavailability of ranitidine in humans [25] and rats [26,31] in a sex-dependent manner whereby such enhancement was only seen in males and not females. This study confirmed that the active effect of PEG 400 is not unique to ranitidine alone but extends to another drug, cimetidine. A bell-shaped curve can be seen in the modulation of $0.3 \% w / v, 0.5 \% w / v$, $0.7 \% w / v$ and $1.0 \% w / v$ PEG 400 in the oral bioavailability of cimetidine. In this study, low doses of PEG $400(0.3 \% w / v-0.7 \% w / v)$ increased the bioavailability of cimetidine, although this was specific to male subjects. Peak enhancement effects were clearly shown in the presence of $0.5 \% w / v$ PEG 400 where unchanged cimetidine excretion was $58 \%$ higher when compared to the control (oral administration of cimetidine alone). The decrease in oral bioavailability upon the co-formulation of $1 \% w / v$ PEG 400 with cimetidine, however, may be attributed to the stimulatory effect of PEG 400 on GI transit. A number of studies have shown that at higher concentrations of PEG 400, small intestinal transit time is reduced by the stimulatory effect of an increased bulk fluid volume in the lumen of the small intestine via osmosis. This consequently limits the time available for drug absorption to occur and as such, drug bioavailability [20,6]. The osmotic effect at higher PEG 400 concentrations, therefore, may supersede over the potential mechanism in increasing cimetidine bioavailability. In female subjects, no significant modulation in unchanged cimetidine excretion was seen in respective PEG 400 doses $(p>0.05)$ (Figure 1). 
Ex vivo studies reflected in vivo drug performance which showed that peak enhancement of cimetidine transport occurred at $0.5 \%$ w/v PEG 400 concentrations (Figure 2). The highest dose of PEG 400 evaluated herein $(1.0 \% \mathrm{w} / \mathrm{v})$, however, led to a similar decrease in cimetidine jejunal absorption males $(-14 \%)$ and females $(-22 \%)$ potentially through the same osmotic action seen in vivo [6].

Such dose-dependent and sex-specific effects have been previously observed for ranitidine; the importance of this finding is paramount, as it provides evidence that PEG 400 affects - at leastanother drug other than ranitidine. This begs the question on how many other drugs may be actively affected by PEG 400. Consequently, it is important to carefully assess the sex-specific effects demonstrated in the light of current knowledge to provide a degree of explanation. What can be assumed is that the mechanisms behind the PEG 400 effect on the bioavailability of ranitidine and cimetidine in humans are similar, if not the same, as seen in rats [27] allowing for a narrowing of the possible reasons.

A sex-specific effect is undisputedly evident, but its reasons may be complex. The most obvious of these differences to consider first are physical, related to both size and physiology between males and females in humans and in rats [40-42]. Sex differences have been observed in the fluid volumes of the human small intestine, with higher absolute fluid volumes measured in males compared to females [43]. This difference could also be responsible for differences in the concentration of drug and PEG 400 in the intestinal lumen in humans, which in turn could affect transit and permeability between the sexes. If we take into consideration that we are observing similar effects of PEG 400 in rats and humans, and given the considerable difference between the rat and human GI luminal environment, we do not believe sex differences in GI luminal environment [28] could be the cause for pronounced difference in the way males and females of both species react to PEG 400.

A possible reason for the sex differences observed could be the variation in drug metabolism in the liver or enterocytes [44-47]. PEG 400 has been shown to modulate CYP3A metabolism [48]. As such, it would be expected that if PEG 400 had an effect on the metabolism and ranitidine, then a difference in excretion should be seen with the parent drug and its metabolites. Ashiru et al., however, identified that the excretion of ranitidine metabolites in both male and female human volunteers followed a similar trend to the parent drug excretion with no observed sex differences [25]. Although it was not specifically investigated herein, it is unlikely that metabolism would explain the sex-specific results in the bioavailability of cimetidine formulated with different concentrations of PEG 400 in male and female volunteers being a similar BCS III/BDDCS III drug compound. As previously proposed, the main reason for the bioavailability enhancing effect of PEG 400 on ranitidine, and cimetidine in this study, may be influenced at the level of the gut from its interaction with membrane transporters present at the luminal environment of the small intestine [26,27].

Ranitidine and cimetidine are known substrates for influx transporters families including organic cation transporters (OCT) and organic anion transporters (OAT) [49,50]. A number of studies have reported that renal and hepatic OCT and OATs have differing expression levels in male and female animal models [51-53]. Although the influence of influx transporters was not studied herein, attention was focused on the impact of excipients on efflux transporters - specifically P-gp-and its modulation towards intestinal drug absorption in male and female subjects. PEG 400 has been previously reported to be capable of interacting with some membrane transporters, although the mechanism behind its modulatory effects are still unknown [5,54]. Cimetidine is also a substrate of P-gp [55-57] and breast cancer resistance protein (BCRP) [58]. A number of studies have reported that P-gp is ubiquitously expressed to a greater extent than BCRP in the human jejunum $[59,60]$ and demonstrate no difference in BCRP mRNA expression in the proximal small intestine of males and females [61]. As such, the study herein investigated the impact of excipients on P-gp alone.

Our results in this paper have shown distinct sex differences in the expression of P-gp and mRNA expression in human male and female small intestinal tissues. The innate difference in baseline P-gp expression in the sexes has consequently led to the sex-specific variation in ex vivo transport of cimetidine in the presence of varying PEG 400 concentrations. Human jejunal tissues were also subjected to PSC 833 for the study of intestinal permeability in the presence of cimetidine and varying concentrations of PEG 400. PSC 833, otherwise known as valspodar, is a derivative of 
cyclosporin D and is widely used as an inhibitor of P-gp. Interestingly, the pre-treatment of human male and female jejunal tissues with PSC 833 increased the transport of cimetidine by $62 \%$ and $19 \%$ respectively. In addition, following PSC 833 treatment, the phenomena of increasing cimetidine transport with PEG 400 concentrations was completely eradicated and showed near identical results to the control (cimetidine alone) (Figure 4). This may allow us to conclude that the modulatory effect of PEG 400 on the efflux transport of P-gp is the main reason for the increase in cimetidine bioavailability in males but not in females. In addition, the distinct difference in P-gp expression and mRNA abundance in the male and female small intestine (Figure 5), however, can provide an explanation as to why low doses of PEG $400(0.3 \% w / v-0.7 \% w / v)$ only affects one sex in the enhancement of cimetidine bioavailability.

There are some supportive findings in other literatures; for instance, one study reported that females have a lower enterocyte P-gp content than in the male small intestine [62]. Since males demonstrate a higher level of intestinal P-gp than females (Figure 5), we propose that by its possible modulation by PEG 400, less cimetidine would be effluxed from the enterocyte to the intestinal lumen. As a result, the concentration of cimetidine would increase from the enterocyte, increasing the amount that would then be absorbed by the systemic circulation. In the case for females, as the abundance of P-gp was significantly lower than males in jejunal tissues, P-gp would not be influenced by the modulated of PEG 400. This may provide a justification as to why PEG 400 only seems to increase the bioavailability of cimetidine in males but not females.

\section{Conclusions}

Pharmaceutically relevant doses of PEG $400(0.3 \% w / v-0.7 \% w / v)$ were found to significantly boost the bioavailability of cimetidine in male but not female human subjects in a dose-dependent manner. The highest evaluated dose of PEG $400(1.0 \% w / v)$ led to a decrease of the bioavailability of cimetidine in both sexes. The postulated mechanism for the enhancement of cimetidine bioavailability in men has been attributed to PEG 400 modulating the intestinal efflux transporter P$\mathrm{gp}$ at gut level as a higher protein and mRNA abundance was identified in male small intestinal tissues when compared with females at the same location. In addition, when jejunal P-gp was inhibited, the sex-specific and dose-dependent effect of PEG 400 on the transport of cimetidine was completed eliminated. PEG 400, therefore, has a modulatory and not inhibitory effect on P-gp. In order to gain a comprehensive understanding of sex differences in treatment response, information on basic physiological differences, participation of both men and women in clinical trials and the analysis of safety and efficacy data are important. As such, it is anticipated that our findings will influence the reconsideration of excipient classification in drug monographs and help determine the clinical consequences of these excipient effects on drug absorption and other pharmacokinetic profiles. This is of notable importance for the case of P-gp substrates for which excipients, such as PEG 400, may otherwise have pronounced effects on drug safety and dosing, and for the potentiation of personalised, sex-specific drug therapeutics.

Author Contributions: Conceptualisation: Y.M., D.A.I.A.-O., A.W.B.; Methodology: Y.M., D.A.I.A.-O., L.D.; Validation: Y.M., D.A.I.A.-O.; Formal analysis: Y.M., D.A.I.A.-O.; Investigation: Y.M., D.A.I.A.-O., L.D.; Resources: Z.Y., A.W.B.; Data curation: Y.M., D.A.I.A.-O.; Writing-Original draft: Y.M., D.A.I.A.-O., C.M.M.; Writing-Review \& Editing: C.M.M., F.T., S.M., A.W.B.; Visualisation: Y.M., D.A.I.A.-O., C.M.M.; Supervision: S.M., A.W.B.; Project administration: A.W.B.; Funding acquisition: C.M.M., S.M., A.W.B. All authors have read and agreed to the published version of the manuscript.

Funding: This research was part funded by the Engineering and Physical Sciences Research Council (EPSRC) UK, grant number EP/L01646X.

Conflicts of Interest: The authors declare no conflict of interest. 


\section{References}

1. Alderborn, G.; Frenning, G. Tablets and compaction. In Aulton's Pharmaceutics: The Design and Manufacture of Medicines; Aulton, M.E., Taylor, K.M.G., Eds.; Elsevier: Amsterdam, The Netherlands, 2017.

2. Reker, D.; Blum, S.M.; Steiger, C.; Anger, K.E.; Sommer, J.M.; Fanikos, J.; Traverso, G. “Inactive” ingredients in oral medications. Sci. Transl. Med. 2019, 11, eaau6753.

3. Chaudhari, S.; Patil, P. Pharmaceutical Excipients: A Review. Int. J. Adv. Pharm. Biol. Chem. 2012, 1, $21-34$.

4. Garcia-Arieta, A. Interactions between active pharmaceutical ingredients and excipients affecting bioavailability: Impact on bioequivalence. Eur. J. Pharm. Sci. 2014, 65, 89-97.

5. Lavan, M.; Knipp, G. Considerations for Determining Direct Versus Indirect Functional Effects of Solubilizing Excipients on Drug Transporters for Enahancing Bioavailability. J. Pharm. Sci. 2020, 109, 18331845.

6. Schulze, J.D.; Waddington, W.A.; Eli, P.J.; Parsons, G.E.; Coffin, M.D.; Basit, A.W. Concentration-dependent effects of polyethylene glycol 400 on gastrointestinal transit and drug absorption. Pharm. Res. 2003, 20, 1984-1988.

7. Stillhart, C.; Vucicevic, K.; Augustijns, P.; Basit, A.W.; Batchelor, H.; Flanagan, T.R.; Gesquiere, I.; Greupink, R.; Keszthelyi, D.; Koskinen, M.; et al. Impact of gastrointestinal physiology on drug absorption in special populations--An UNGAP review. Eur. J. Pharm. Sci. 2020, 147, 105280.

8. Zarmpi, P.; Flanagan, T.; Meehan, E.; Mann, J.; Fotaki, N. Biopharmaceutical aspects and implications of excipient variability in drug product performance. Eur. J. Pharm. Biopharm. 2017, 111, 1-15.

9. Batrakova, E.V.; Li, S.; Li, Y.; Alakhov, V.Y.; Kabanov, A.V. Effect of pluronic P85 on ATPase activity of drug efflux transporters. Pharm. Res. 2004, 21, 2226-2233.

10. Al-Ali, A.A.A.; Steffansen, B.; Holm, R.; Nielsen, C.U. Nonionic surfactants increase digoxin absorption in Caco-2 and MDCKII MDR1 cells: Impact on P-glycoprotein inhibition, barrier function, and repeated cellular exposure. Int. J. Pharm. 2018, 551, 270-280.

11. Mai, Y.; Dou, L.; Madla, C.M.; Murdan, S.; Basit, A.W. Sex-Dependence in the Effect of Pharmaceutical Excipients: Polyoxyethylated Solubilising Excipients Increase Oral Drug Bioavailability in Male but not Female Rats. Pharmaceutics 2019, 11, 228.

12. Elder, D.P.; Kuentz, M.; Holm, R. Pharmaceutical excipients-quality, regulatory and biopharmaceutical considerations. Eur. J. Pharm. Sci. 2016, 87, 88-99.

13. Flanagan, T. Potential for pharmaceutical excipients to impact absorption: A mechanistic review for BCS Class 1 and 3 drugs. Eur. J. Pharm. Biopharm. 2019, 141, 130-138.

14. Soldin, O.P.; Chung, S.H.; Mattison, D.R. Sex differences in drug disposition. J. Biomed. Biotechnol. 2011, 2011, 187103.

15. Zhang, W.; Li, Y.; Zou, P.; Wu, M.; Zhang, Z.; Zhang, T. The Effects of Pharmaceutical Excipients on Gastrointestinal Tract Metabolic Enzymes and Transporters-an Update. AAPS J. 2016, 18, 830-843.

16. Freire, A.C.; Basit, A.W.; Choudhary, R.; Piong, C.W.; Merchant, H.A. Does sex matter? The influence of gender on gastrointestinal physiology and drug delivery. Int. J. Pharm. 2011, 415, 15-28.

17. Gandhi, M.; Aweeka, F.; Greenblatt, R.M.; Blaschke, T.F. Sex differences in pharmacokinetics and pharmacodynamics. Annu. Rev. Pharmacol. Toxicol. 2004, 44, 499-523.

18. Hatton, G.B.; Yadav, V.; Basit, A.W.; Merchant, H.A. Animal Farm: Considerations in Animal Gastrointestinal Physiology and Relevance to Drug Delivery in Humans. J. Pharm. Sci. 2015, 104, 2747-2776.

19. Taherali, F.; Varum, F.; Basit, A.W. A slippery slope: On the origin, role and physiology of mucus. Adv. Drug Deliv. Rev. 2018, 124, 16-33.

20. Basit, A.W.; Newton, J.M.; Short, M.D.; Waddington, W.A.; Ell, P.J.; Lacey, L.F. The effect of polyethylene glycol 400 on gastrointestinal transit: Implications for the formulation of poorly-water soluble drugs. Pharm. Res. 2001, 18, 1146-1150.

21. Schulze, J.D.; Peters, E.E.; Vickers, A.W.; Staton, J.S.; Coffin, M.D.; Parsons, G.E.; Basit, A.W. Excipient effects on gastrointestinal transit and drug absorption in beagle dogs. Int. J. Pharm. 2005, 300, 67-75.

22. Schulze, J.D.; Ashiru, D.A.; Khela, M.K.; Evans, D.F.; Patel, R.; Parsons, G.E.; Coffin, M.D.; Basit, A.W. Impact of formulation excipients on human intestinal transit. J. Pharm. Pharmacol. 2006, 58, 821-825.

23. Ashiru-Oredope, D.A.; Patel, N.; Forbes, B.; Patel, R.; Basit, A.W. The effect of polyoxyethylene polymers on the transport of ranitidine in Caco-2 cell monolayers. Int. J. Pharm. 2011, 409, 164-168.

24. Basit, A.W.; Podczeck, F.; Newton, J.M.; Waddington, W.A.; Ell, P.J.; Lacey, L.F. Influence of polyethylene glycol 400 on the gastrointestinal absorption of ranitidine. Pharm. Res. 2002, 19, 1368-1374. 
25. Ashiru, D.A.; Patel, R.; Basit, A.W. Polyethylene glycol 400 enhances the bioavailability of a BCS class III drug (ranitidine) in male subjects but not females. Pharm. Res. 2008, 25, 2327-2333.

26. Afonso-Pereira, F.; Murdan, S.; Sousa, J.; Veiga, F.; Basit, A.W. Sex differences in excipient effects: Enhancement in ranitidine bioavailability in the presence of polyethylene glycol in male, but not female, rats. Int. J. Pharm. 2016, 506, 237-241.

27. Mai, Y.; Afonso-Pereira, F.; Murdan, S.; Basit, A.W. Excipient-mediated alteration in drug bioavailability in the rat depends on the sex of the animal. Eur. J. Pharm. Sci. 2017, 107, 249-255.

28. Dou, L.; Gavins, F.K.H.; Mai, Y.; Madla, C.M.; Taherali, F.; Orlu, M.; Murdan, S.; Basit, A.W. Effect of Food and an Animal's Sex on P-Glycoprotein Expression and Luminal Fluids in the Gastrointestinal Tract of Wistar Rats. Pharmaceutics 2020, 12, 296.

29. Dou, L.; Mai, Y.; Madla, C.M.; Orlu, M.; Basit, A.W. P-glycoprotein expression in the gastrointestinal tract of male and female rats is influenced differently by food. Eur. J. Pharm. Sci. 2018, 123, 569-575.

30. Mai, Y.; Dou, L.; Murdan, S.; Basit, A.W. An animal's sex influences the effects of the excipient PEG 400 on the intestinal P-gp protein and mRNA levels, which has implications for oral drug absorption. Eur. J. Pharm. Sci. 2018, 120, 53-60.

31. Mai, Y.; Murdan, S.; Awadi, M.; Basit, A.W. Establishing an in vitro permeation model to predict the in vivo sex-related influence of PEG 400 on oral drug absorption. Int. J. Pharm. 2018, 542, $280-287$.

32. Bebawy, M.; Chetty, M. Gender differences in p-glycoprotein expression and function: Effects on drug disposition and outcome. Curr. Drug Metab. 2009, 10, 322-328.

33. Benet, L.Z.; Broccatelli, F.; Oprea, T.I. BDDCS applied to over 900 drugs. AAPS J. 2011, 13, 519-547.

34. Davis, S.S. Formulation strategies for absorption windows. Drug Discov. Today 2005, 10, $249-257$.

35. Food and Drug Administration. Bioavailability and Bioequivalence Requirements; Food and Drug Administration: Silver Spring, MD, USA, 2019.

36. Somogyi, A.; Gugler, R. Clinical pharmacokinetics of cimetidine. Clin. Pharmacokinet. 1983, 8, $463-495$.

37. Ashiru, D.A.; Patel, R.; Basit, A.W. Simple and universal HPLC-UV method to determine cimetidine, ranitidine, famotidine and nizatidine in urine: Application to the analysis of ranitidine and its metabolites in human volunteers. J. Chromatogr. B Anal. Technol. Biomed. Life Sci. 2007, 860, 235-240.

38. Albin, H.; Vincon, G.; Lalague, M.C.; Couzigou, P.; Amouretti, M. Effect of sucralfate on the bioavailability of cimetidine. Eur. J. Clin. Pharmacol. 1986, 30, 493-494.

39. Berardi, R.R.; Tankanow, R.M.; Nostrant, T.T. Comparison of famotidine with cimetidine and ranitidine. Clin. Pharm. 1988, 7, 271-284.

40. Afonso-Pereira:, F.; Dou, L.; Trenfield, S.J.; Madla, C.M.; Murdan, S.; Sousa, J.; Veiga, F.; Basit, A.W. Sex differences in the gastrointestinal tract of rats and the implications for oral drug delivery. Eur. J. Pharm. Sci. 2018, 115, 339-344.

41. Merchant, H.A.; Rabbie, S.C.; Varum, F.J.; Afonso-Pereira, F.; Basit, A.W. Influence of ageing on the gastrointestinal environment of the rat and its implications for drug delivery. Eur. J. Pharm. Sci. 2014, 62, 76-85.

42. Vertzoni, M.; Augustijns, P.; Grimm, M.; Koziolek, M.; Lemmens, G.; Parrott, N.; Pentafragka, C.; Reppas, C.; Rubbens, J.; Van Den Alphabeele, J.; et al. Impact of regional differences along the gastrointestinal tract of healthy adults on oral drug absorption: An UNGAP review. Eur. J. Pharm. Sci. 2019, 134, 153-175.

43. Gotch, F.; Nadell, J.; Edelman, I.S. Gastrointestinal Water and Electrolytes. 4. The Equilibration of Deuterium Oxide (D2o) in Gastrointestinal Contents and the Proportion of Total Body Water (Tbw) in the Gastrointestinal Tract. J. Clin. Investig. 1957, 36, 289-296.

44. Axiotis, C.A.; Guarch, R.; Merino, M.J.; Laporte, N.; Neumann, R.D. P-Glycoprotein Expression Is Increased in Human Secretory and Gestational Endometrium. Lab. Investig. 1991, 65, 577-581.

45. Kagan, L.; Dreifinger, T.; Mager, D.E.; Hoffman, A. Role of P-Glycoprotein in Region-Specific Gastrointestinal Absorption of Talinolol in Rats. Drug Metab. Dispos. 2010, 38, 1560-1566.

46. Lindell, M.; Karlsson, M.O.; Lennernas, H.; Pahlman, L.; Lang, M.A. Variable expression of CYP and Pgp genes in the human small intestine. Eur. J. Clin. Investig. 2003, 33, 493-499.

47. Rademaker, M. Do women have more adverse drug reactions? Am. J. Clin. Dermatol. 2001, 2, 349-351.

48. Johnson, B.M.; Charman, W.N.; Porter, C.J. An in vitro examination of the impact of polyethylene glycol 400, Pluronic P85, and vitamin E d-alpha-tocopheryl polyethylene glycol 1000 succinate on P-glycoprotein efflux and enterocyte-based metabolism in excised rat intestine. AAPS PharmSci 2002, 4, E40. 
49. Bourdet, D.L.; Pollack, G.M.; Thakker, D.R. Intestinal absorptive transport of the hydrophilic cation ranitidine: A kinetic modeling approach to elucidate the role of uptake and efflux transporters and paracellular vs. transcellular transport in Caco-2 cells. Pharm. Res. 2006, 23, 1178-1187.

50. Kimura, N.; Masuda, S.; Tanihara, Y.; Ueo, H.; Okuda, M.; Katsura, T.; Inui, K. Metformin is a superior substrate for renal organic cation transporter OCT2 rather than hepatic OCT1. Drug Metab. Pharmacokinet. 2005, 20, 379-386.

51. Buist, S.C.; Cherrington, N.J.; Choudhuri, S.; Hartley, D.P.; Klaassen, C.D. Gender-specific and developmental influences on the expression of rat organic anion transporters. J. Pharmacol. Exp. Ther. 2002, 301, 145-151.

52. Urakami, Y.; Nakamura, N.; Takahashi, K.; Okuda, M.; Saito, H.; Hashimoto, Y.; Inui, K. Gender differences in expression of organic cation transporter OCT2 rat kidney. FEBS Lett. 1999, 461, 339-342.

53. VanWert, A.L.; Gionfriddo, M.R.; Sweet, D.H. Organic anion transporters: Discovery, pharmacology, regulation and roles in pathophysiology. Biopharm. Drug Dispos. 2010, 31, 1-71.

54. Otter, M.; Oswald, S.; Siegmund, W.; Keiser, M. Effects of frequently used pharmaceutical excipients on the organic cation transporters 1-3 and peptide transporters 1/2 stably expressed in MDCKII cells. Eur. J. Pharm. Biopharm. 2017, 112, 187-195.

55. Arnold, Y.E.; Thorens, J.; Bernard, S.; Kalia, Y.N. Drug Transport across Porcine Intestine Using an Ussing Chamber System: Regional Differences and the Effect of P-Glycoprotein and CYP3A4 Activity on Drug Absorption. Pharmaceutics 2019, 11, 139.

56. Collett, A.; Higgs, N.B.; Sims, E.; Rowland, M.; Warhurst, G. Modulation of the permeability of H-2 receptor antagonists cimetidine and ranitidine by P-glycoprotein in rat intestine and the human colonic cell line Caco-2. J. Pharmacol. Exp. Ther. 1999, 288, 171-178.

57. Lentz, K.A.; Polli, J.W.; Wring, S.A.; Humphreys, J.E.; Polli, J.E. Influence of passive permeability on apparent P-glycoprotein kinetics. Pharm. Res. 2000, 17, 1456-1460.

58. Pavek, P.; Merino, G.; Wagenaar, E.; Bolscher, E.; Novotna, M.; Jonker, J.W.; Schinkel, A.H. Human breast cancer resistance protein: Interactions with steroid drugs, hormones, the dietary carcinogen 2-amino-1methyl-6-phenylimidazo(4,5-b)pyridine, and transport of cimetidine. J. Pharmacol. Exp. Ther. 2005, 312, 144152.

59. Drozdzik, M.; Groer, C.; Penski, J.; Lapczuk, J.; Ostrowski, M.; Lai, Y.; Prasad, B.; Unadkat, J.D.; Siegmund, W.; Oswald, S. Protein abundance of clinically relevant multidrug transporters along the entire length of the human intestine. Mol. Pharm. 2014, 11, 3547-3555.

60. Vaessen, S.F.; van Lipzig, M.M.; Pieters, R.H.; Krul, C.A.; Wortelboer, H.M.; van de Steeg, E. Regional Expression Levels of Drug Transporters and Metabolizing Enzymes along the Pig and Human Intestinal Tract and Comparison with Caco-2 Cells. Drug Metab. Dispos. 2017, 45, 353-360.

61. Gutmann, H.; Hruz, P.; Zimmermann, C.; Beglinger, C.; Drewe, J. Distribution of breast cancer resistance protein (BCRP/ABCG2) mRNA expression along the human GI tract. Biochem. Pharmacol. 2005, 70, 695-699.

62. Potter, J.M.; McWhinney, B.C.; Sampson, L.; Hickman, P.E. Area-under-the-curve monitoring of prednisolone for dose optimization in a stable renal transplant population. Ther. Drug Monit. 2004, 26, 408414. 